\section{MATTERS ARISING \\ Antiperinuclear factors are present in polyarthritis before ACR criteria for rheumatoid arthritis are fulfilled}

\section{Pain in the rheumatic diseases}

We were very interested to read Professor Croft's article ${ }^{1}$ about pain in the rheumatic diseases because we are interested in studying the relation between patients' perception of disease and objective signs. ${ }^{2}$ In the daily management of a cohort of approximately 600 patients with inflammatory arthritis at Poole Hospital we noticed a dissociation between reported pain and objective measures of disease activity in a number of patients.

To further study this phenomenon we randomly selected a sample of 100 patients with rheumatoid arthritis (mean (SD) age $=63$ (12) years, $73 \%$ rheumatoid factor positive). We looked at the pattern of change of reported pain $(10 \mathrm{~cm}$ visual analog scale (VAS)), number of swollen joints (EULAR 28 articular index), and serum $C$ reactive protein (CRP, normal $<10 \mathrm{mg} / \mathrm{l})$ in the previous two years.

We identified a close linear relation in 72 patients. In 18 patients pain was repeatedly reported at not less than $20 \mathrm{mms}$ VAS despite no evidence of disease activity (CRP $<10$ $\mathrm{mg} / \mathrm{l}$ and swollen joint count $=0$ ) at any point during their follow up. In 10 patients pain was repeatedly scored as absent despite disease activity markers reflecting joint inflammation (CRP $>15 \mathrm{mg} / \mathrm{l}$, with or without $>2$ swollen joints). Fifteen of 18 patients showing pain but no disease activity were rheumatoid factor positive and there was no obvious difference in the degree of joint deformity clinically although detailed assessment of joint damage radiologically was not made.

These preliminary data support our contention that, in about one third of patients followed up in a district general hospital, there is a dissociation between reported pain and objective signs of joint inflammation These differences may be related to joint damage in the patients with pain but no disease activity but cannot be so explained in those patients with disease activity but no pain. A more detailed analysis of these patients may reveal the reasons for this dissociation. In the meantime we suggest that rheumatologists might consider managing pain separately from disease activity in some of their patients. We also urge caution in interpreting summated disease activity indices that include pain and joint tenderness as major parts of their score.

P W THOMPSON Poole Hospital NHS Trust, Poole, Dorset ALISON J CARR
Outcomes Research Unit, Kings College Hospital, Denmark Hill, London

Correspondence to: Dr P W Thompson, Poole Hospital, Longfleet Road, Poole, Dorset BH15 2JB.

1 Croft P. The epidemiology of pain: the more you have, the more you get. Ann Rheum Dis 1996; 55:859-60.

2 Carr AJ, Thompson PW. Towards a measure of patient-perceived handicap in rheumatoi arthritis. Br J Rheumatol 1994;33:378-82.
We were interested in the study by Berthelot and colleagues, in which they studied the predictive value of the antiperinuclear factor (APF) for rheumatoid arthritis.

The authors concluded that APFs are useful in the diagnosis of early rheumatoid arthritis. They mentioned that recognition of the true value of APF has long been hindered by methodical errors. Serum samples were only diluted $1: 5$ or $1: 10$, even though the APF titre can reach 1:20 000 in rheumatoid artritis serum samples and is usually above $1: 200$.

We would like to make some comments especially concerning the method they used. The method used differs not only in the dilution of the serum samples, for screening $1: 100$ and if positive they were further diluted $1: 200,1: 500,1: 1000$ to determine the end point titre, but it differs also in the way of regarding the positivity of the tests. They refer to their study published in 1990, in which a dilution of $1: 80$ is used. In 1990 Westgeest et al described for the first time the influence of serum dilution on findings of the APF prevalence in rheumatoid arthritis (RA). ${ }^{2}$ So authors of the study on an interlaboratory variability test for RA (1993) from the representing laboratories in Amsterdam, Brest, Gent, and Nijmegen came together to discuss their different methods for the APF determination and to reach a standard protocol. This protocol was used for a quantitative assessment of the method, using the WHO standard rheumatoid artritis serum as a reference serum. The results of coded serum samples from five separate patients were blindly tested in the five laboratories. The methods used were not harmonised. Four laboratories defined the titre of a serum by the highest dilution, which gave a clearly positive result, while the laboratory in Brest, to which Berthelot and colleagues also refer, also considered the percentage of cells that were stained. ${ }^{3}$ The results of the five laboratories showed only small interlaboratory variations. The interlaboratory variations were again reduced by comparison with the results with the WHO standard rheumatoid arthritis serum and thereby expressing the results in IU instead of litres, this study is not mentioned in Dr Berthelot's study. ${ }^{1}$ So linked to the uniformity of the results, we think that the value of the APF is not hindered by the method.

In our longitudinal evaluation during methotrexate and azathioprine treatment for $\mathrm{RA}$, the highest APF titre was 1:640. ${ }^{4}$ In the study by Berthelot et al the APF titre can reach 1:20 000 in rheumatoid arthritis serum samples.

Did Berthelot and colleagues use another method than that they used in the intervariability study?

AGNES M T H BOERBOOMS University Hospital Nijmegen, the Netherlands

\footnotetext{
1 Berthelot JM, Maugars Y, Castagne, Audrain M, Prost A. Antiperinuclear factors are present in polyarthritis before ACR criteria for rheuin polyarthritis before ACR criteria for rheu-
matoid arthritis are fulfilled. Ann Rheum Dis 1997;56:123-5.
}

2 Westgeest AAA, Boerbooms AMTh, Van de Putte LBA. The influence of serum dilution
on findings of antiperinuclear factor prevaon findings of antiperinuclear factor preva-
lence in rheumatoid arthritis. Arthritis Rheum lence in rheumat

3 Feltkamp TEW, Berthelot JM, Boerbooms AMTh, Geertzen HGM, Hoet R, De Keyzer $\mathrm{F}$, et al. Interlaboratory variability of the antiperinuclear factor (APF) test for rheumatoid arthritis. Clin Exp Rheumatol 1993; 11:57-9.

4 Kerstens PJSM, Boerbooms AMTh, Jeurissen MEC, Westgeest AAA, Van Erp A, Mulder J, et MEC, Westgeest AAA, Van Erp A, Mulder J, et al. Antiperinuclear factor and disease activity in rheumatoid arthritis. Longitudinal evaluation during methotrexate and azathioprin therapy. J Rheumatol 1994;21:2190-4.

\section{Authors' reply}

We gratefully acknowledge Dr Boerbooms for her valuable comments on our antiperinuclear factor (APF) paper. ${ }^{1}$ Her statement is correct. Five European groups set up a consensus study on the interlaboratory variability of the APF test in 1993. ${ }^{2}$ Despite the use of different cells, conjugates, and criteria for positivity, their results were comparable for the five serum samples tested. Given that there is a risk that any artefact could be mistaken for a stained granule, we feel, however, that it is useful to take into account the proportion of stained cells, ${ }^{3}$ as suggested by others. ${ }^{4}$ Similarly Dr Westgeest and Boerbooms underlined themselves the importance of serum dilution, ${ }^{5}$ the same year when Youinou et al proposed to increase it up to $1: 80$ instead of $1: 5 .^{4}$ We recently identified another source of poor results (that is, to delay the test several days after fixation of the slides). ${ }^{6} \quad$ Regarding our much better sensitivity, Dr Boerbooms is also aware that the suitability of particular buccal mucosa cells is unpredictable. The possibility therefore exists that donors vary from one country or laboratory to another, and actually more than $70 \%$ of our donor's cells exhibit large granules. We fully agree with $\mathrm{Dr}$ Boerbooms that the APF test warrants being used on a regular basis. We recently came across the literature and believe that the APF test has been underevaluated. To conclude, we thank Dr Boerbooms for the opportunity to debate these technical details, although we quite respect her choice of an older but still valuable method: for instance Westgeest and Boerbooms could confirm the findings of Katahaa $^{7}$ that APF can also be found in some infectious mononucleosis serum samples, and suggested that Epstein-Barr virus might be a co-factor in the breakdown of tolerance towards profilaggrin. ${ }^{8}$ Although direct evidence for this assumption is still lacking, our recent findings of a strong $\mathrm{T}$ cell response towards Epstein-Barr virus lytic cycle antigens in RA joints might indicate that their hypothesis was correct. ${ }^{9}$

J-M BERTHELOT

Clinique de Rhumatologie, Centre Hospitalier et Universitaire, Place Alexis Ricordeau, BP 1005, 44035 Nantes cedex 01, France

1 Berthelot JM, Maugars Y, Castagné A, Audrain $\mathrm{M}$, Prost A. Antiperinuclear factors are present in polyarthritis before ACR criteria for rheumatoid arthritis are fulfilled. Ann Rheum Dis 1997;56:123-5

2 Feltkamp TEW, Berthelot JM, Boerbooms AMT, Geertzen H, Hoet RM, De Ketser F, et al. Interlaboratory variability of the antiperinuclear factor (APF) test for rheumatoid nuclear factor (APF) test for rheumatoid

3 Berthelot JM, Castagne A, Maugars Y, Audrain $M$, Barrier J, Prost A. High diagnostic value of antiperinuclear factor-IgG: Prospective analy- 
sis of 1,004 sera diluted $1: 100$ and more. $\mathrm{Br} J$ Rheumatol 1995;34:87-8.

4 Youinou P, Le Goff P, Dumay A, Lelong A Fauquert P, Jouquan J. The antiperinuclea factor. 1. Clinical and serologic associations. Clin Exp Rheumatol 1990;8:259-64.

5 Westgeest AAA, Boerbooms AMT, van de Putte LBA. The influence of serum dilution on finding of antiperinuclear factor prevalence in rheumatoï arthritis. Arthritis Rheum 1990 33:759-60.

6 Berthelot JM. Antiperinuclear factor in the polyarticular form of juvenile chronic arthritis: are use of frozen material or age of patients relevant? Ann Rheum Dis 1995;54:76-8.

7 Katahaa PK, Mortazavi-Milani SM, Russel G, Holborow EJ. Anti-intermediate filament antiHolborow Ej. Anti-intermediate filament antibodies, antikeratin antibody, and antiperinuin rheumatord arthritis an infectious monor

8 Westgeest AAA, Van Loon AM, Van Der Logt JTM, Van De Putte LBA, Boerbooms AMT Antiperinuclear factor, a rheumatoid arthritisspecific autoantibody: Its relation to Epstein Barr virus. J Rheumatol 1989;16:626-30.

9 Scotet E, David-Ameline J, Peyrat MA Moreau-Aubry A, Pinczon D, Lim A, et al. T-cell response to Epstein-Barr virus transactivators in chronic rheumatoid arthritis. J Exp Med 1996;184:1791-800

\section{LETTER}

\section{rhG-CSF resistant neutropenia in SLE}

Suppression of the haematopoietic system, especially of the myeloid lineage, is a severe complication of systemic lupus erythematosus (SLE). ${ }^{1}$ In a recent report Euler et al suggested rhG-CSF as an effective treatment of neutropenia during SLE, especially during infection resistant to antibiotic treatment. ${ }^{2}$ We present a case of a girl with SLE whose neutropenia did not respond to rhG-CSF and who subsequently succumbed to untreatable fungal sepsis.

A previously healthy 9.5 year old girl developed SLE presenting with six of $11 \mathrm{cri}$ teria of the American College of Rheumatology including butterfly rash, oral ulcers, arthritis, and serositis. Laboratory investigations demonstrated ANA+, anti-dsDNA+, hypocomplementaemia, but normal white blood cell count. Eight months after initial remission she had a relapse, presenting with neutropenia $(650$ neutrophils/ $\mu \mathrm{l}, \quad 800$ lymphocytes/ $\mu \mathrm{l}$ ) and signs of nephritis. Bone marrow biopsy examination showed a general suppression of all myeloid lineages including megacaryocytes but showed a relative increase of the red blood cell lineage. Over the next months neutropenia was resistant to several pulses of intravenous methylprednisolone therapy ( $250 \mathrm{mg} /$ day), to cyclophosphamide intravenous pulse treatment (500 $\mathrm{mg} / \mathrm{m}^{2}$ ), and to intravenous IgG therapy $(2 \mathrm{~g} / \mathrm{kg})$. Because of the prolonged increase in serum transaminase activities the cyclophosphamide pulse therapy was interrupted and the immunosuppression was changed to a combination of oral prednisone, azathioprine, and cyclosporine A, which slightly diminished disease activity but had no influence on neutropenia. A second bone marrow biopsy examination gave a similar result as described above. After two months the girl was admitted to hospital presenting with signs of sepsis and went into a coma and developed a progressive respiratory insufficiency. Thoracic and cranial computed tomography and nuclear magnetic resonance showed several abscess-like infiltrates in both lungs and brain. Antibiotic treatment, including amphotericine-B, was ineffective despite detection of aspergillus fumigatus infection by blood cultures. On the assumption that neutropenia $(740 / \mu \mathrm{l})$ is an important factor in the pathogenesis of infection resistant to therapy, we started treatment with $\mathrm{rhG}-\mathrm{CSF}$ in a dose of $7.5 \mu \mathrm{g} / \mathrm{kg} /$ day over 10 days. Before starting rhG-CSF therapy the bone marrow aspirate showed a hypocellularity but no maturation arrest of the myeloid series. The application of rhG-CSF had no effect on the number of peripheral neutrophils (about 600 cells $/ \mu \mathrm{l}$ ). Subsequently the condition of the girl worsened and the patient died in terminal respiratory insufficiency.

There are two reports demonstrating successful rhG-CSF treatment of neutropenia during SLE. In a 56 year old woman suffering from SLE and sepsis white blood cell count rose from $400 / \mu 1$ to $17200 / \mu$ l after treatment with $100 \mu \mathrm{g} /$ day $\mathrm{rhG}-\mathrm{CSF}$ over five days. ${ }^{3}$ The second report showed an increase of neutrophil counts in three women (23-36 years) with neutropenia during SLE after application of four cycles of $5 \mu \mathrm{g} / \mathrm{kg} /$ day $\mathrm{rhG}-$ CSF from a mean of 1060 to $14300 \mathrm{cells} / \mu$ within 48 hours. Fever of unknown origin subsided in all three cases, in addition, in one case a gluteal abscess healed after this treatment. ${ }^{2}$ In contrast with our case all of these previously published case reports showed normal or increased granulopoiesis in bone marrow aspirates. ${ }^{23}$ The patients reported by Euler et al did not receive methylprednisolone, cyclophosphamide or IgG pulse therapy, which may have influenced rhG-CSF stimulation on bone marrow cells in our patient by cytotoxic effects. However, neutropenia was present before immunosuppressive therapy and bone marrow analysis did not change significantly during the course of disease. There are at least two possibilities that could explain the failure of rhG-CSF treatment in this case. (1) The block of myeloid cell production may have been located before rhG-CSF action on bone marrow cells. (2) Autoantibodies against rhG-CSF may inhibit the effects of this factor as described earlier for treatment with erythropoietin. Lack of maturation arrest in bone marrow analysis and the fact that this was the first contact of our patient with rhG-CSF do not support these theories. Thus, the pathophysiological mechanisms leading to response or non-response of rhG-CSF treatment in SLE associated neutropenia are still not clear.

In our opinion this case shows that rhG-CSF application is not generally an effective treatment of SLE associated neutropenia. Hypocellularity of bone marrow aspirates and lack of prompt response seem to be a prognostic unfavourable factor regarding the beneficial effect of rhG-CSF treatment.

$$
\begin{array}{r}
\text { MICHAEL FROSCH } \\
\text { JOHANNES ROTH } \\
\text { ERIK HARMS } \\
\text { Department of Paediatrics, University of } \\
\text { Münster, Albert-Schweitzer-Str 33, } \\
48149 \text { Münster, Germany }
\end{array}
$$

Correspondence to: Dr J Roth.

Keeling D M, Isenberg D A. Haematological manifestations of systemic lupus erythematomanifestations of systemic lupus
sus. Blood Rev 1993;7:199-207.

2 Euler H H, Schwab U M, Schroeder J O. Filgrastim for lupus neutropenia. Lancet 1994;344:1513-4

3 Kondo H, Date Y, Sakai Y, Akimoto M. Effective simultaneous rhG-CSF and methylprednisolone "pulse" therapy in agranulocytosis associated with systemic lupus erythematosus. Am J Hematol 1994;46:157-8. 